19 Revue d'histoire du XIXe siècle

Société d'histoire de la révolution de 1848 et des

révolutions du XIXe siècle

$39 \mid 2009$

Le monde de l'imprimé: des territoires aux acteurs -

Education et politique - Histoires politiques

\title{
Samuel GICQUEL, Prêtres de Bretagne au XIX siècle
}

Rennes, Presses universitaires de Rennes, 2008, 310 p. ISBN :

978-2-7535-0667-1. 20 euros.

Guillaume Cuchet

\section{OpenEdition}

Journals

Édition électronique

URL : http://journals.openedition.org/rh19/3964

DOI : $10.4000 /$ rh 19.3964

ISSN : $1777-5329$

Éditeur

La Société de 1848

Édition imprimée

Date de publication : 10 décembre 2009

Pagination : 181-182

ISSN : 1265-1354

\section{Référence électronique}

Guillaume Cuchet, "Samuel GICQUEL, Prêtres de Bretagne au XIXe siècle », Revue d'histoire du XIXe siècle [En ligne], 39 | 2009, mis en ligne le 26 mars 2010, consulté le 22 septembre 2020. URL : http:// journals.openedition.org/rh19/3964 ; DOI : https://doi.org/10.4000/rh19.3964

Ce document a été généré automatiquement le 22 septembre 2020.

Tous droits réservés 


\section{Samuel GICQUEL, Prêtres de Bretagne au XIX siècle}

Rennes, Presses universitaires de Rennes, 2008, 310 p. ISBN :

978-2-7535-0667-1. 20 euros.

\section{Guillaume Cuchet}

1 Le livre est consacré aux carrières de quelque 7300 prêtres des diocèses de Vannes et Saint-Brieuc pendant la période concordataire. L'auteur étudie l'ampleur et l'évolution des flux, la diversité des trajectoires professionnelles (paroissiales, non-paroissiales, fonctions de direction), les contrastes et la mobilité géographiques, les facteurs de réussite ou d'échec des carrières, les relations entre prêtres, le développement de l'esprit de corps, l'évolution des modèles de vie sacerdotale et le rôle de la frontière linguistique. Le tout est accompagné d'un bel ensemble d'annexes même si - l'éditeur aurait pu s'en aviser - certaines reproductions sont de si mauvaise qualité qu'elles sont presque indéchiffrables (par exemple les documents 7 et 12a). En revanche, il faut accorder une mention particulière aux très belles et très parlantes pyramides des âges du clergé établies aux dates de 1807, 1827, 1857 et 1905 (p. 279-280). Non que l'on ignorât tout à fait jusque-là les évolutions qu'elles manifestent - la profonde échancrure due au choc de la Révolution et à l'absence d'une génération qui n'a été ni recrutée ni rattrapée, le rajeunissement massif de l'époque de la Restauration, etc. -, mais elles leur donnent un relief et une force explicative particulières.

2 L'auteur explique qu'on n'a guère étudié jusqu'ici les carrières du clergé français au XIX siècle du point de vue prosopographique. Louis Rousseau a donné l'exemple pour le clergé québécois. La thèse inédite de Jean-Pierre Gonnot sur le diocèse de Belley entre 1823 et 1904 (Lyon II, 1984) portait davantage sur la question de la vocation que sur les carrières proprement dites. Les périodes plus anciennes, en revanche, ont déjà fait l'objet de travaux de ce genre. Pour le XVIII siècle sont mentionnés les travaux de Viviane Barrie-Curien sur le clergé londonien et de Ségolène de Dainville-Barbiche sur le clergé parisien. On peut ajouter - même s'il ne s'agit pas de prêtres diocésains, il s'agit tout de même d'histoire religieuse du XIX ${ }^{e}$ siècle - la thèse de Jacques-Olivier Boudon sur l'épiscopat concordataire, celle de Philippe Boutry sur la curie romaine à 
l'âge de la Restauration et, tout récemment, celle de Matthieu Bréjon de Lavergnée sur les membres des conférences Saint-Vincent-de-Paul ${ }^{1}$.

3 Les deux diocèses retenus ont la particularité d'être à la fois traversés par la frontière linguistique qui sépare Haute et Basse-Bretagne et particulièrement riches en vocations religieuses, tant masculines que féminines. Le diocèse de Vannes, en termes de taux d'ordination, est même encore plus fécond que celui de Saint-Brieuc. Ce qui est vrai à l'échelle nationale l'est encore à l'échelle bretonne puisqu'ils tiennent la tête du classement devant Quimper et Nantes et à peu près à égalité avec Rennes. Cette situation se traduit dans leur contribution au recrutement national : ils rassemblent $4,16 \%$ des prêtres français pour 3 à $3,1 \%$ de la population. Les meilleures années, on ordonnait au XIXe siècle jusqu'à 40 prêtres à Saint-Brieuc et 30 à Vannes ${ }^{2}$. En reconstituant la courbe des ordinations, l'auteur a retrouvé à peu de choses près celle qu'avait établie en 1950 pour la France le chanoine Boulard. La spécificité des deux diocèses bretons tient surtout dans le fait qu'ils anticipent de quelques années sur les évolutions générales, qu'il s'agisse des "années noires » 1804-1806 - le creux de la vague post-révolutionnaire -, des ordinations massives de l'époque de la Restauration, de la prospérité des années 1861-1876 et 1896-1905. La courbe dépend de la conjoncture politique, c'est-à-dire de l'attitude des régimes en place, selon qu'elle est plus ou moins favorable aux intérêts de l'Église, mais aussi du nombre de postes vacants et donc des perspectives de carrière pour les candidats. La mise en évidence de ce mode de "régulation interne" du recrutement sacerdotal, sur lequel Boulard n'avait guère insisté dans son livre, est un point important. On aurait aimé en savoir davantage sur la manière dont cela se passait concrètement mais ici, sans doute, les sources font défaut pour répondre de façon pleinement satisfaisante.

4 La Révolution s'étant traduite par une décléricalisation brutale et massive, les trois premières décennies du siècle sont marquées par le manque de prêtres et les postes vacants mais aussi - aspects positifs de la crise - par les études accélérées et la rapidité des promotions. Les choses changent autour de 1830 : l'afflux massif de jeunes prêtres sous la Restauration provoque - autre point fort de la démonstration - un "spectaculaire blocage des carrières » (p. 273), blocage d'autant plus net qu'on est ici dans des diocèses exceptionnellement fertiles. Le vicariat, qui fonctionnait jusqu'alors comme un sas que l'on franchissait rapidement, tend à devenir une étape longue du cursus honorum. La perspective d'une accession rapide au poste de succursaliste, $a$ fortiori de curé inamovible, s'éloigne, sans que l'on constate au demeurant dans ces diocèses bien encadrés de mouvements de protestation dans le clergé.

La solution viendra du développement des fonctions non-paroissiales après 1860 (peutêtre déjà avant ?), c'est-à-dire de l'enseignement, des aumôneries, des congrégations masculines et des missions. Cette diversification « donne de l'air » à un système qui en manquait et permet de résoudre partiellement le problème de l'encombrement des carrières qui avait marqué les années 1830-1850. L'auteur fait des remarques éclairantes sur le rôle de la frontière linguistique dans la gestion des carrières. Ses recherches lui permettent d'affiner la carte de la frontière linguistique établie par le folkloriste Paul Sébillot en 1886. Du point de vue des carrières, le fait majeur est que cette frontière est quasiment étanche. À part quelques « coucous » gallos isolés en pays bretonnant - l'inverse est rarissime -, on ne la franchit guère. Du coup, même si le problème n'est pas très grave compte tenu du haut niveau général des effectifs, les 
évêques ne peuvent pas utiliser de façon vraiment optimale leur personnel en faisant jouer les vases communicants.

6 Les derniers chapitres sur les formes de dévotion, les critères de recrutement et l'évolution des modèles sacerdotaux sont peut-être moins originaux mais l'auteur fait des remarques suggestives sur plusieurs points, en particulier l'esprit de corps dans le clergé.

\section{NOTES}

1. Jacques-Olivier Boudon, L'épiscopat français à l'époque concordataire : 1802-1905. Origines, formation, nomination, Paris, Le Cerf, 1996 ; Philippe Boutry, Souverain et pontife. Recherches prosopographiques sur la Curie romaine à l'âge de la Restauration: 1814-1846, Paris, École française de Rome, 2002 ; Matthieu Brejon de Lavergnée, La société Saint-Vincent-de-Paul au XIX siècle, 1833-1871. Un fleuron du catholicisme social, Paris, Le Cerf, 2008. Voir le compte-rendu de cet ouvrage par Gilles Ferragu dans la Revue d'histoire du XIX ${ }^{\mathrm{e}}$ siècle, $\mathrm{n}^{\circ}$ 38, 2009/1, p. 152-154. 